\title{
IDENTIFIKASI POTENSI JERUK PURUT SEBAGAI DEMULSIFIER UNTUK MEMISAHKAN AIR DARI EMULSI MINYAK DI LAPANGAN MINYAK RIAU
}

\section{IDENTIFICATION OF POTENTIAL KAFFIR LIME AS DEMULSIFIER TO SEPARATE WATER FROM OIL EMULSION IN RIAU'S OIL FIELD}

\author{
Tomi Erfando*, Novia Rita, Sonya Regina Cahyani \\ Program Studi Teknik Perminyakan, Fakultas Teknik, Universitas Islam Riau, Pekanbaru, Indonesia \\ *Corresponding Author : tomierfando@eng.uir.ac.id
}

Submit : 05 Maret 2018

Accepted : 17 Mei 2018

\begin{abstract}
Emulsion stability is an indicator that needs to be controlled to prevent the degradation of petroleum quality. Emulsion breakdown is one of the mechanisms to separate the water phase from oil. It is transformed into a chemical compound that is expected to function as emulsion blocking or commonly known as a demulsifier. An organic demulsifier is one of the right ideas in preventing environmental pollution without diminishing its main function as an emulsion breaker. The bottle test method is one of the most commonly used methods in demulsification tests. Testing using this method is done by inserting the prepared emulsion into the bottle, then it will be placed into a waterbath under certain temperature conditions for several hours. This test will be done by looking at the demulsification that occurs every 30 minutes. From the testing of temperature, concentration, and effectiveness of the formulated formula, an optimal condition is obtained based on the highest demulsification efficiency. Based on the research, optimal condition of organic demulsifier formula is $\left(3 \mathrm{ml}, 80^{\circ} \mathrm{C}\right)$ with $7 \mathrm{ml}$ demulsification efficiency. The results obtained from organic material formulations have not been able to increase the effectiveness of emulsion-breaking processes compared to commercial demulsifiers and basecase conditions $(20 \mathrm{ml})$.
\end{abstract}

Keywords: demulsifier, emulsion, lime, bottle test

\section{PENDAHULUAN}

Saat proses produksi, umumnya minyak dan gas bumi akan terproduksi bersama air. Air yang diproduksikan terjadi dalam dua cara,yaitu sebagian air dapat diproduksi sebagai free water, dan sebagian air dapat diproduksi dalam bentuk emulsi. Emulsi adalah dispersi tetesan air dalam minyak [1]. Emulsi merupakan sifat muatan pada partikel yang ukurannya jauh lebih kecil daripada tetesan emulsi yang mereka stabilkan [2].

Untuk meminimalisasi masalah produksi terkait dengan emulsi minyak dan masalah lingkungan, teknisi atau operator terkait perlu mencegah pembentukan emulsi dengan memecahkan emulsi tersebut. Emulsifikasi air dalam minyak biasanya sulit terjadi karena ketidaksempurnaan antara kedua fase cair ini. Namun, shear mixing yang terjadi pada cairan selama produksi dan adanya surfaktan alami dalam komposisi minyak bumi berkontribusi terhadap pembentukan emulsi tersebut [3]. Ketika emulsi air dalam minyak semakin stabil, maka air akan terdispersi dengan baik di dalam minyak sehingga proses demulsifikasi akan semakin sulit untuk dilakukan. Hal ini terjadi karena emulsi merupakan campuran heterogen yang terdiri dari sekurang-kurangnya satu cairan yang terdispersi dengan baik dalam bentuk tetesan, sehingga sulit untuk memisahkan minyak mentah murni dari emulsi. Emulsi minyak mentah merupakan hal yang tidak diinginkan, sehingga memisahkan minyak mentah dari emulsi merupakan tantangan dalam industri penghasil minyak saat ini [4].

Ketika minyak bercampur dengan air, maka tingkat kualitas serta ekonomis dari minyak mentah akan semakin berkurang. Dengan demikian, diperlukannya formulasi demulsifier untuk memisahkan air dari emulsi minyak sehingga kualitas dari minyak akan semakin baik. Dalam pembuatan formulasi demulsifier tentunya harus memikirkan dampak dari komposisi yang digunakan, terutama terhadap lingkungan. Semakin ketatnya standar dan keamanan untuk 
bahan kimia di lapangan minyak, adanya dorongan yang signifikan untuk mengembangkan formulasi yang lebih ramah lingkungan untuk diaplikasian di lapangan minyak, yang dilakukan seefisien mungkin dengan menggunakan bahan kimia yang ada [5].

Dalam penelitian ini, akan dilakukan percobaan untuk mengetahui potensi jeruk purut sebagai demulsifier. Penelitian ini dilakukan di Laboratorium Reservoir Teknik Perminyakan Univeristas Islam Riau. Penelitian dilakukan guna memperkecil dampak negatif dari penggunaan bahan kimia terhadap lingkungan maupun fisik. Sehingga evaluasi pada formulasi demulsifier berbahan lokal terhadap demulsifier konvensional dilakukan guna untuk menguji efektifitas dari formulasi yang akan dibuat. Hal ini dilakukan agar dapat menghasilkan demulsifier yang efektif dan ramah lingkungan.

\section{METODOLOGI PENELITIAN}

Peralatan yang digunakan dalam pembuatan formulasi adalah alat perasan jeruk, batang pengaduk, pisau, saringan. Untuk uji Bottle Test, adalah botol berukuran $100 \mathrm{ml}$, gelas kimia $50 \mathrm{ml}$, gelas kimia $250 \mathrm{ml}$, gelas kimia $300 \mathrm{ml}$, gelas ukur $10 \mathrm{ml}$, gelas ukur $25 \mathrm{ml}$, heater, labu volumetrik, neraca digital, dan waterbath. Sampel minyak pada salah satu Lapangan di Riau diperoleh dari ketersediaan minyak yang terdapat di Laboratorium Reservoir Teknik Perminyakan. Sampel minyak lapangan ini akan digunakan sebagai emulsi yang akan diuji efektifitas pemisahan ketika ditambahkan dengan demulsifier guna mengetahui besarnya pengaruh penambahan demulsifier berbahan lokal dalam memecahkan emulsi minyak. Berikut merupakan beberapa karakteristik fisik dari minyak pada lapangan tersebut.

Dalam pembuatan demulsifier, bahan lokal yang digunakan adalah Jeruk Purut. Beberapa Jeruk Purut disiapkan, kemudian diperas, disaring dan dituangkan ke dalam gelas ukur dengan volume yang berbeda-beda, yaitu $1 \mathrm{ml}, 3 \mathrm{ml}$, dan $5 \mathrm{ml}$. Pengaruh suhu terhadap proses demulsifikasi dilakukan dengan menvariasikan suhu pemanasan. Sampel emulsi minyak lapangan yang telah homogen dengan formulasi demulsifier akan dipanaskan dengan variasi suhu $60^{\circ} \mathrm{C}, 70^{\circ} \mathrm{C}$, dan $80^{\circ} \mathrm{C}$ selama 3 jam. Pemilihan suhu terbaik berdasarkan persentase pemisahan air tertinggi.

\section{HASIL DAN PEMBAHASAN}

Formula demulsifier organik yang berbahan dasar jeruk purut. Jeruk purut merupakan jenis jeruk yang memiliki kandungan asam sitrat. Asam sitrat (naphthenic acid) memiliki efisiensi demulsifikasi yang tinggi dikarenakan memiliki lebih banyak gugus karboksil yang lebih tinggi dari asam lainnya, sehingga efisiensi demulsifikasi asam sitrat memiliki nilai yang tinggi. Selain itu, asam sitrat merupakan jenis asam yang tidak beracun, tidak menimbulkan iritasi, dan ramah lingkungan [6]. Asam sitrat juga mudah ditemukan pada bahan organik sejenis jeruk (citrus) termasuk jeruk purut (citrus hystrix). Kandungan asam sitrat yang terdapat dalam jeruk purut (sejenis lime) adalah $45.8 \mathrm{~g} / \mathrm{L}$ [7].

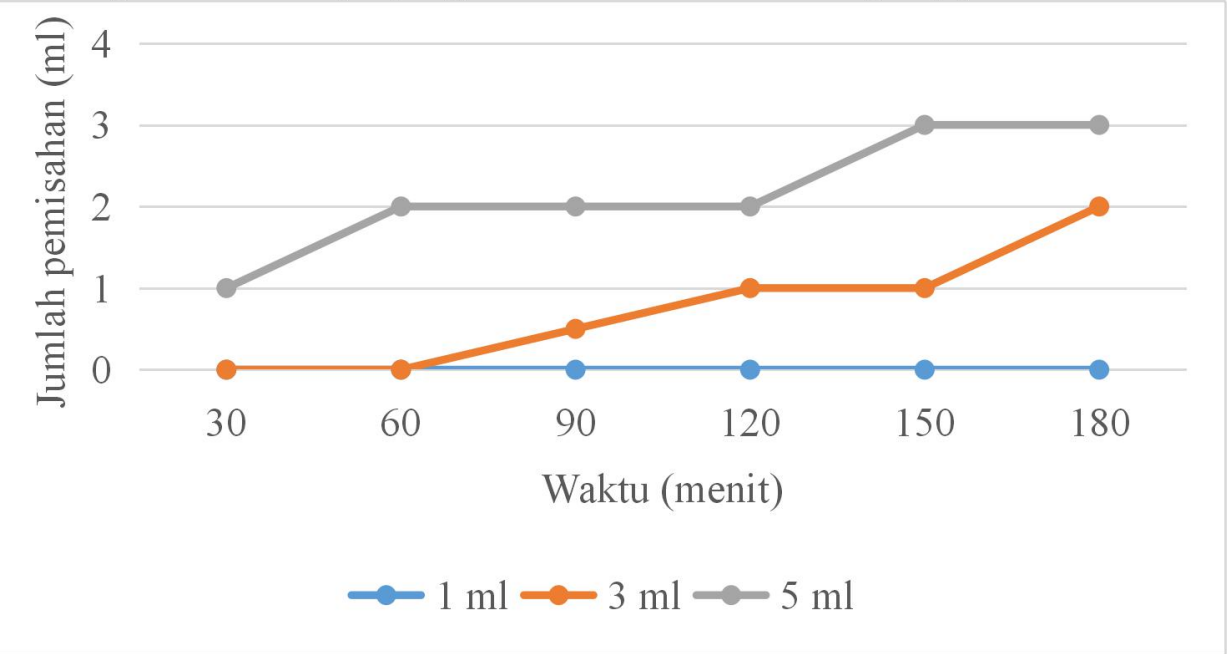

Gambar 1. Hasil pemisahan pada suhu $60^{\circ} \mathrm{C}$

Pada gambar 1 merupakan pengujian pada suhu $60^{\circ} \mathrm{C}$ dengan menggunakan air perasan jeruk purut sebanyak $1 \mathrm{ml}, 3 \mathrm{ml}$, dan $5 \mathrm{ml}$.
Terlihat hasil yang diberikan untuk sangat rendah sekali, dengan konstrasi 1 dan $3 \mathrm{ml}$ tidak ada air yang terpisah dari emulsi minyak selama 60 
menit pertama. Hal ini mungkin saja terjadi karena jeruk purut tidak mampu bekerja secara optimal dengan konsentrasi dan suhu yang rendah. Sedangkan dari segi water quality, formula ini cenderung larut terhadap minyak dibandingkan dengan air. Sehingga, air tidak terkontaminasi dengan perasan jeruk purut tersebut dan menghasilkan water quality yang cukup baik, seperti yang dapat dilihat pada gambar 1.

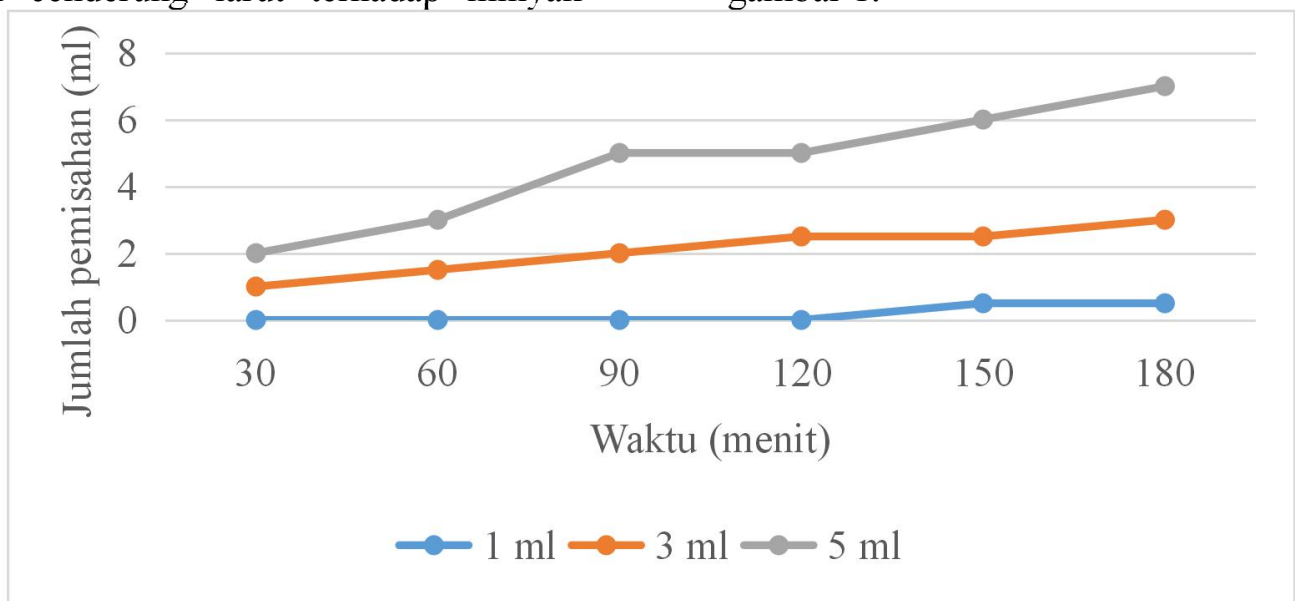

Gambar 2. Hasil pemisahan pada suhu $70^{\circ} \mathrm{C}$

Menjadi acuan keberhasilan pengujian demulsifier dari jeruk purut ini adalah demulsifier komersial. Hasil pemisahan demulsifier konvensional ini adalah sebesar 20 $\mathrm{ml}$ dan stabil disemua variasi suhu. Pada suhu yang lebih tinggi yaitu $70^{\circ} \mathrm{C}$ tingkat keberhasil lebih baik dari percobaan di suhu $60^{\circ} \mathrm{C}$, hasil dapat di lihat pada gambar 2 dan gambar 4. Dengan waktu perendaman 30 menit telah menunjukan pemisah sebesar $1 \mathrm{ml}$ untuk konstrasi jeruk purut $3 \mathrm{ml}$ dan pemisahan sebesar $2 \mathrm{ml}$ dengan konsentrasi $5 \mathrm{ml}$. Hasil terbaik diperoleh pada konsentrasi jeruk purut sebesar 5 $\mathrm{ml}$ menujukan pemisahan air dan emulsi sebanyak $7 \mathrm{ml}$ setelah direndam pada waterbath selama 180 menit. Sementara itu untuk suhu $80^{\circ} \mathrm{C}$ diperolehan terbaik dari konsterasi jeruk 3 $\mathrm{ml}$ setelah perendaman selama 180 menit, dengan jumlah pemisahan sebesar $7 \mathrm{ml}$ (gambar
3). Konsentrasi $1 \mathrm{ml}$ dan $5 \mathrm{ml}$ justru tidak memberikan hasil yang baik.

Berdasarkan data yang didapatkan efisiensi kinerja dari formula ini yang paling optimal adalah $5 \mathrm{ml}$ pada suhu $70^{\circ} \mathrm{C}$ dan $3 \mathrm{ml}$ pada suhu $80^{\circ} \mathrm{C}$ yaitu sebesar $7 \mathrm{ml}$. Dari hasil tersebut dapat dikatakan bahwa formula ini cukup aman untuk digunakan dalam meminimalisir dampak lingkungan serta limbah berbahaya. Namun, perlu adanya tambahan bahan kimia yang cukup aman untuk meningkatkan kinerja efisiensi demulsifikasi dari jeruk purut. Untuk dapat melihat peningkatan yang lebih terstruktur dari efisiensi demulsifikasi dapat dilihat berdasarkan data yang telah ditransformasikan ke dalam grafik sebagai berikut beserta contoh pemisahan dan water quality yang paling baik dari formula ini pada gambar 2 .

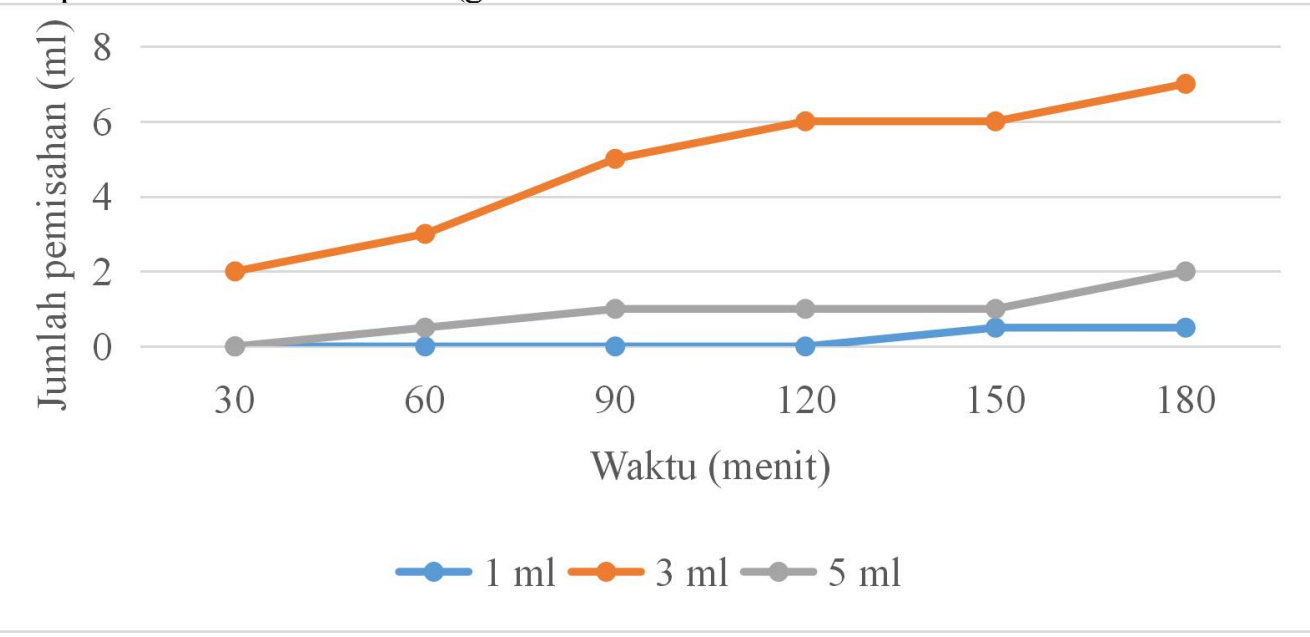


Gambar 3. Hasil pemisahan pada suhu $80^{\circ} \mathrm{C}$
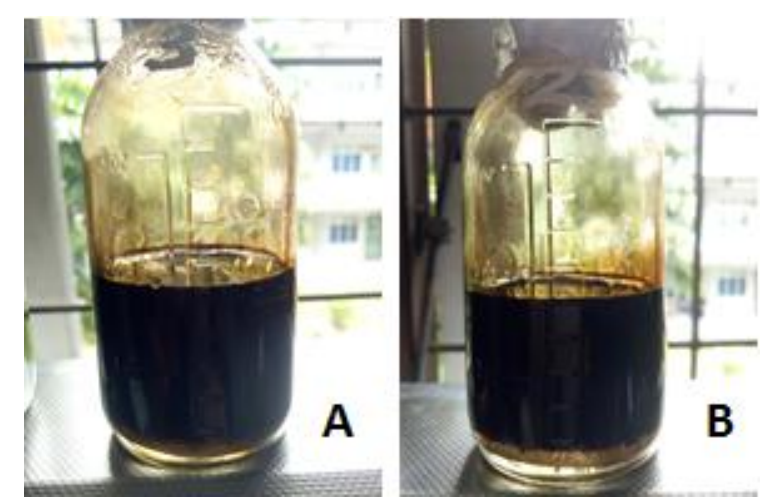

Gambar 4. Demulsifikasi tertinggi dan water quality terbaik pada formula (A) Sampel $1\left(5 \mathrm{ml} ; 70^{\circ} \mathrm{C}\right)$ dan (B) Sampel $\left(3 \mathrm{ml} ; 80^{\circ} \mathrm{C}\right)$

\section{KESIMPULAN}

Efisiensi kinerja dari formula ini yang paling optimal adalah $5 \mathrm{ml}$ pada suhu $70^{\circ} \mathrm{C}$ dan $3 \mathrm{~m} 1$ pada suhu $80^{\circ} \mathrm{C}$ yaitu sebesar $7 \mathrm{ml}$. Hasil yang diperoleh dari bahan organik berupa jeruk purut belum mampu meningkatan efektivitas proses pemecahan emulsi dibandingkan dengan demulsifier komersil dan kondisi basecase (sebesar $20 \mathrm{ml}$ ).

\section{UCAPAN TERIMA KASIH}

Terima kasih ditujukan kepada Lembaga Penelitian dan Pengabdian kepada Masyarakat Universitas Islam Riau atas dukungan terlaksananya penelitian ini.

\section{DAFTAR PUSTAKA}

[1] Kokal, S., \& Al-Juraid, J. (1999). Quantification of various factors affecting emulsion stability: watercut, temperature, shear, asphaltene content, demulsifier dosage and mixing different crudes. SPE Annual Technical Conference and Exhibition, 56641. https://doi.org/10.2118/56641-MS

[2] [2] Wylde, J. J., Coscio, S., \& Barbu, V. (2008). A case history of heavy oil separation in northern alberta: a singular challenge of demulsifier optimization and application. 2008 SPE International Thermal Operations and Heavy Oil Symposium, 1-8.

[3] [3] Hajivand, P., \& Vaziri, A. (2015). Optimization of demulsifier formulation for separation of water from crude oil emulsions. Brazilian Journal of Chemical Engineering, 32(1), https://doi.org/10.1590/0104-

6632.20150321s00002755

[4] [4] Emuchay, D., Onyekonwu, M. O., Ogolo, N. A., \& Ubani, C. (2013). Breaking of emulsions using locally formulated demusifiers. $\quad$ SPE, 167528. https://doi.org/10.2118/167528-MS

[5] [5]Zhou, H., Dismuke, K., Lett, N., \& Penny, G. (2012). Development of more environmentally friendly demulsifiers. $S P E$ International Symposium and Exhibition on Formation Damage Control, 151852 (February). https://doi.org/10.2118/151852MS

[6] [6] Liu, D., Suo, Y., Zhao, J., Zhu, P., Tan, J., Wang, B., \& Lu, H. (2018). Effect of demulsification for crude oil-in-water emulsion: comparing co and organic acids. Energy and Fuels, 32(1). https://doi.org/10.1021/acs.energyfuels.7b03 334

[7] [7]L., K., Penniston, M. D., Stephen Y. Nakada, M. D., Ross P. Holmes, P. D., \& Dean G. Assimos, M. D. (2008). Quantitative assessment of citric acid in lemon juice, lime juice, and commerciallyavailable fruit juice products. Journal of Endourology, 34(2), 567-570. https://doi.org/10.1089/end.2007.0304 
